\title{
Infestação mista por Lynxacarus radovskyi e Felicola subrostratus em um gato na região de Porto Alegre, RS, Brasil
}

\author{
Mixed infestation by Lynxacarus radovskyi and Felicola subrostratus \\ in a cat in Porto Alegre, RS, Brazil \\ Juliana Aguiar', Mauro Luis da Silva Machado², Rafael Rodrigues Ferreira ${ }^{2}$, \\ Paula Stieven Hünning ${ }^{1}$, Adriana Cunha Muschner ${ }^{3}$ \& Roselia Zazycky Ramos ${ }^{3}$
}

RESUMO

A linxacariose é uma doença incomum que acomete felinos, principalmente em regiões tropicais, porém há registros também em regiões subtropicais. No Brasil, foi descrita pela primeira vez em 1986, e atualmente existem relatos em todas as regiões, excluindo o centro-oeste do país. No Rio Grande do Sul, somente alguns casos foram relatados no ano de $1997 \mathrm{em}$ felinos das raças persa e exótico. Esta doença é causada pela infestação do ácaro Lynxacarus radovskyi. Algumas vezes, esta infestação pode estar associada a outras parasitoses externas, na qual a mais comum é a pediculose por Felicola subrostratus, parasita de distribuição mundial. Geralmente, a transmissão é dada por contato direto ou por fômites, mas não é considerada uma doença de alto contágio. Os animais infestados apresentam variado grau de prurido, alopecia, disqueratinização, pelagem opaca e pelos aparentemente com sujidades, tradicionalmente com o aspecto "sal e pimenta". Algumas vezes, a manifestação clínica da doença pode ser confundida com outras dermatopatias, não sendo corretamente diagnosticada. O diagnóstico é dado pela visualização direta do ácaro e por microscopia óptica. O objetivo do relato é descrever um caso de infestação por L. radoviskyi associado com F. subrostratus, em um felino sem raça definida atendido no Serviço de Dermatologia, Hospital de Clínicas Veterinárias da Universidade Federal do Rio Grande do Sul, Porto Alegre, RS.

Descritores: linxacariose, pediculose, felinos.

\begin{abstract}
Lynxacariosis is an uncommon parasitic disease in felines recorded in tropical, and sometimes subtropical, regions of varied countries. In Brazil lynxacariosis was first described in 1986, in Rio de Janeiro, and currently there are reports in all regions of the country, excluding the central-west region. In Rio Grande do Sul, only a few cases were reported in 1997 in Persian Exotic cats. The disease is caused by the infestation of the mite Lynxacarus radovskyi. Sometimes this infestation can be mixed with other external parasitoses, most commonly with the pediculosis caused by Felicola subrostratus, a parasite distributed worldwide. Usually the transmission occurs by direct contact or by fomites, but it is not considered as a highly transmissible disease. The infested animals present variable degree of pruritus, alopecia, scalling, and a "salt and pepper" appearance to the dull and dirty coat. Sometimes the clinical manifestation of the disease can be confused with other dermatitis, not being correctly diagnosed. The diagnosis is confirmed by the direct visualization of the mite and by optic microscopy. The objective of this article is to report a case of infestation by $L$. radoviskyi associated with $F$. subrostratus in a mixed cat, attended at the Service of Dermatology, Hospital de Clínicas Veterinárias of the Universidade Federal do Rio Grande do Sul (UFRGS), Porto Alegre, RS, Brazil.
\end{abstract}

Keywords: lynxacariosis, pediculosis, felines. 


\section{INTRODUÇÃO}

A linxacariose é considerada uma doença incomum em gatos e tem como agente etiológico o Lynxacarus radovskyi, um ácaro sarcoptiforme, da família Listrophoridae [5,9,12]. São ácaros pequenos, de $0,5 \mathrm{~mm}[3,11], 430$ a $515 \mu \mathrm{c}$ de comprimento [5,20], geralmente estão aderidos ao terço distal da haste pilosa, e podem ser visualizados a olho nu [20]. A infecção geralmente ocorre por contato direto, mas fômites podem ser importantes na transmissão [3,7]. Os animais parasitados parecem estar sujos, pois como o ácaro se adere aos pelos, apresentam um aspecto salpicado, de "sal e pimenta", além de alopecia e prurido $[5,11$, $12,20]$. Os pelos epilam-se com facilidade, a derme apresenta-se normal, ou com erupções papulares, característica de dermatite miliar [12]. A infestação por este ácaro geralmente ocorre em países de clima tropical [3], mas já foi relatada em regiões de clima subtropical [7]. A primeira descrição foi em 1974, por Tenório, no Havaí, [21] e há relatos em poucos países, tais como: Porto Rico, Austrália, Estados Unidos, Ilhas Fiji, Brasil e Nova Zelândia $[6,9,13,17]$. No Brasil, foi relatada nos estados do Rio de Janeiro [4], Pará [19], Pernambuco [1], Bahia [8], São Paulo [10,13], Rio Grande do Sul [16], Rio Grande do Norte [18] e Alagoas [15]. Algumas vezes, esta doença pode ser observada associada a outras, causadas por ectoparasitas e a mais comum delas é a pediculose [2,17]. Piolhos da espécie Felicola subrostratus pertencem a subordem Mallophaga e são encontrados em todas as regiões do mundo. São mastigadores e movimentam-se rapidamente pelo corpo dos animais. As áreas mais afetadas são face, pinas e região dorsal. Os gatos infestados apresentam grau de prurido variado. Animais sensíveis, com prurido intenso, podem apresentar dermatites graves, semelhantes às causadas por alergias à parasitas externos, cursando com alopecia, escoriações e infecção bacteriana secundária [20]. Neste artigo, é relatado um caso de infestação mista por $L$. radovskyi e $F$. subrostratus em um felino mestiço, na cidade de Porto Alegre, RS, Brasil.

\section{RELATO DE CASO}

Felino, macho, castrado, sem raça definida (SRD), de quatro anos de idade, proveniente de uma casa com pátio de um bairro de Porto Alegre, RS, foi atendido no Serviço de Dermatologia do Hospital de Clínicas Veterinárias da UFRGS. O animal apresentava prurido generalizado, lesões alopécicas multifocais, descamação e dermatite úmida. No exame clínico, observou-se um padrão distributivo de dermatite miliar, assim como a presença de ectoparasitas aderidos às hastes pilosas, configurando o aspecto tradicional de linxacariose - "sal e pimenta" (Figura 1). No exame direto de pelos sob microscopia (aumento de 100x), observou-se ácaros de Lynxacarus radovskyi (Figura 2) e piolhos da espécie Felicola subrostratus (Figura 3). $\mathrm{Na}$ mesma propriedade, havia outros gatos, com sintomas mais brandos, porém não se observou em nenhum outro animal o padrão "sal e pimenta", e, no exame direto dos pelos destes gatos, foram observados apenas piolhos da espécie $F$. subrostratus. Todos os animais foram tratados com Fipronil spray ${ }^{\circledR 1}$ mensalmente, por dois meses, havendo regressão completa do quadro clínico. Foi recomendado uso mensal de fipronil para prevenção de novas infestações por ectoparasitas.

\section{DISCUSSÃO}

A linxacariose é pouco evidenciada em felinos da região de Porto Alegre, RS, e existe somente um relato na literatura [16] em felinos de raças persa e exótico provenientes de um gatil. A infestação por Felicola subrostratus é mais comumente observada, porém a associação entre estes dois parasitas nunca havia sido constatada e relatada neste estado, embora muitas destas infestações podem passar despercebidas, devido ao fato de que muitos animais apresentam sinais clínicos e manifestações leves [5].

Os sinais clínicos envolvem disqueratinização cutânea, alopecia [7,12], disqueratose furfurácea ou laminar, pelagem com aspecto ressequido [20], perda de pelo [4,12,17], pelagem fosca [17] escoriações [7] e, em casos mais severos, infecção bacteriana secundária. O prurido pode estar presente ou não $[3,4,7,12,13,16$, 17,19]. A localização dos ácaros é mais frequente na região perianal, nos membros posteriores e na cauda, e o parasitismo parece ser mais comum em machos [7]. No presente relato, o animal apresentava prurido generalizado, dermatite miliar e o padrão "sal e pimenta". Além disso, observou-se associação mista de Lynxacarus radovskyi com Felicola subrostratus. Seus contactantes não possuíam infestação por $L$. radovskyi, mas apenas por $F$. subrostratus. A linxacariose pode ocorrer em uma pequena parcela de gatos, mesmo dentro de um grupo maior de animais, pois não é considerada de alto contágio [5]. Como há relatos de grande intercorrência $(37,02 \%)$ entre a infestação das duas doenças, como nas 


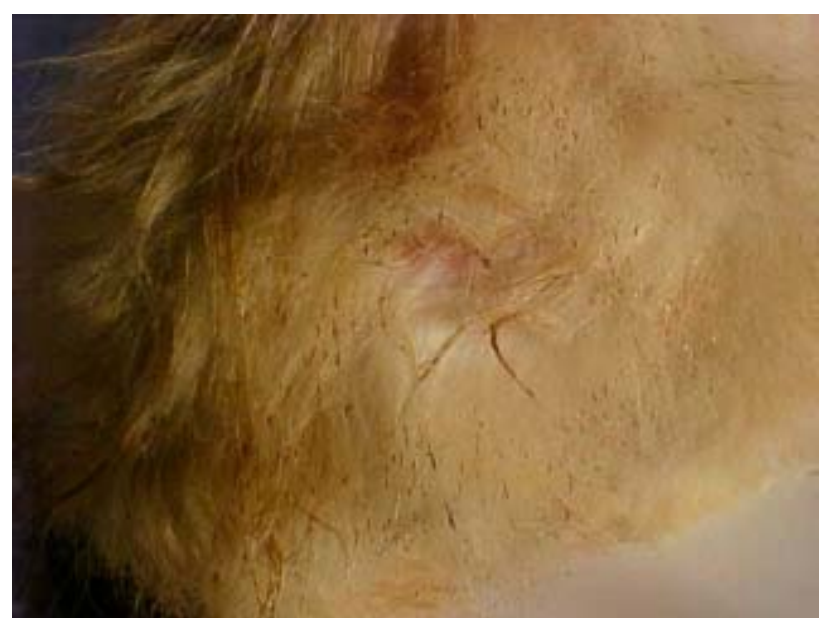

Figura 1. Dermatite miliar e presença de ectoparasitas aderidos às hastes pilosas, configurando o aspecto tradicional de linxacariose - "sal e pimenta". Felino macho, castrado, SRD de 4 anos de idade.

cidades de Recife, em Pernambuco [17], e Vila Velha, no Espírito Santo [2], o diagnóstico diferencial é de extrema importância, embora muitas vezes passe despercebido pelo médico veterinário. Linxacariose, puliciose e pediculose são atualmente incomuns em gatos domésticos em regiões de alto poder aquisitivo, provavelmente porque os tratamentos convencionais para pulgas também são eficazes para o combate destas doenças. Por outro lado, é comum em animais errantes, de vida livre, que vivem em altas concentrações ou convivem com animais selvagens [12].

O diagnóstico é baseado na visualização direta dos ácaros aderidos aos pelos [6,12], usando uma lupa ou através da microscopia [6], raspado de pele [5,11], decalque (inprint) [11] ou ainda por meio de avulsão do pelame [5]. O exame de microscopia óptica deve compreender a colocação do material entre lâmina e lamínula, adicionadas de 2 a 3 gotas de hidróxido de potássio a $10 \%$ e observadas em objetiva de 10x [5]. Os parasitos ou ovos podem ser também visualizados nas fezes, devido aos hábitos de lambedura dos felinos [5]. O diagnóstico foi confirmado através da microscopia óptica e também pela visualização direta dos ácaros aderidos aos pelos.

O tratamento instituído foi Fipronil spray ${ }^{\circledR}$, com aplicação mensal. Ao término do tratamento, os animais não apresentavam mais os sinais visualizados anteriormente, e, por ocasião da microscopia direta, não foram mais observados ácaros Lynxacarus radovskyi nem Felicola subrostratus, com melhora de $100 \%$ do quadro clínico. O tratamento dos parasitas externos em

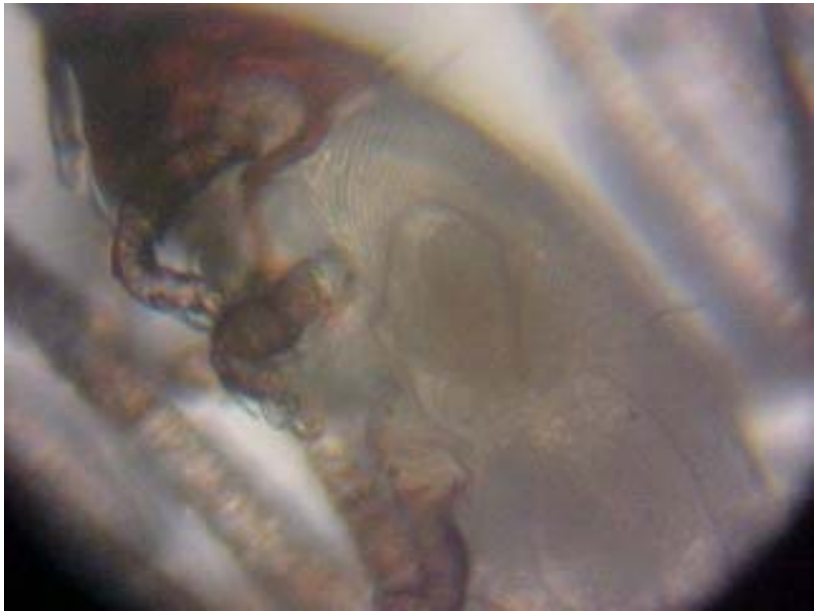

Figura 2. Microscopia direta dos pêlos. Observa-se o ácaro Lynxacarus radovskyi (100x).

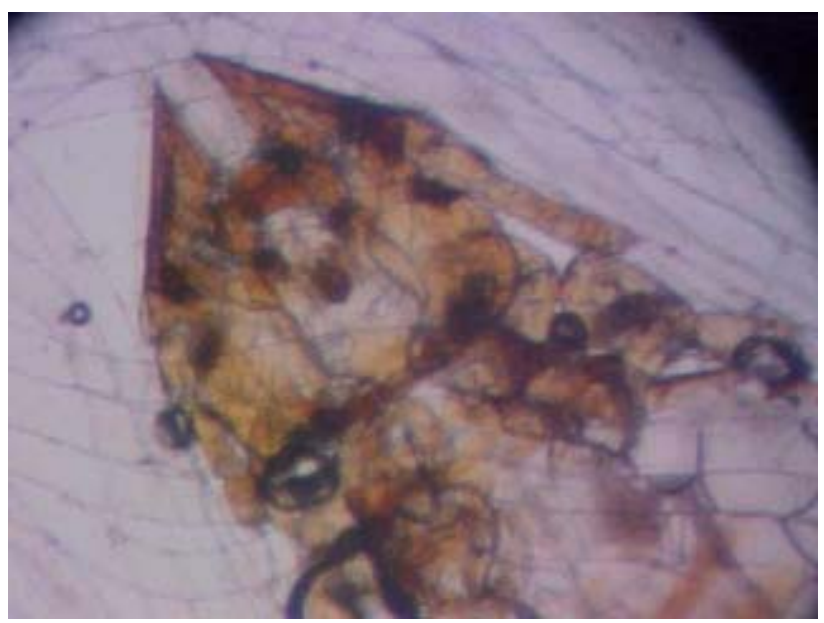

Figura 3. Microscopia direta. Piolho da espécie Felicola subrostratus $(100 \mathrm{x})$.

felinos baseia-se no uso de pulicidas, que, na maioria dos casos, também são piolhicidas [20]. Estes podem ser aplicados em forma de xampu, pó ou imersão [5]. Para o tratamento ideal, incluindo a morte dos ovos, indica-se terapia por 5 semanas consecutivas [6]. Podem ser usados imidacloprida, selamectina, fipronil, xampus a base de piretrina $[3,5,12,16]$ e carbaryl pó a $5 \%$ [5,12]. Banho semanal com xampu a base piretrina, durante quatro semanas, mostrou-se eficaz na eliminação do ácaro, não sendo observada nova infestação por um período de um ano após o tratamento [3], embora em alguns casos a infestação tenha sido reduzida, mas não eliminada com três banhos em três dias intercalados [16]. O sulfeto de selênio, aplicado corretamente em banhos semanais, é uma boa opção inicial, assim como o tetraetil-tiuram [19]. A ivermectina é eficiente, quando usada semanalmente, durante quatro semanas 
[12]. Observou-se que, na dosagem de $0,3 \mathrm{mg} \cdot \mathrm{kg}^{-1} \mathrm{SC}$, a droga apresenta um efeito drástico sobre a população do ácaro [7]. O fipronil, tanto na utilização spray como "pour on" tem sido recomendado como tratamento eficiente e seguro para controle de parasitos externos em gatos [14].

Recomenda-se também, o tratamento secundário com antimicrobianos, corticosteróides ou outras medicações, quando se tornar necessário [7]. Além disso, é preconizada a prevenção com uso frequente de acaricidas [20].

\section{CONCLUSÕES}

A linxacariose associada à pediculose é incomum em gatos. Este é o primeiro relato em gatos SRD no Rio Grande do Sul. Atenta-se para o conhecimento do clínico de pequenos animais que esta doença, embora de rara ocorrência, existe no sul do Brasil e que as manifestações clínicas podem ser confundidas com outras dermatopatias. Considera-se uma doença de fácil diagnóstico e tratamento.

NOTAS INFORMATIVAS

${ }^{1}$ Frontline spray ${ }^{\circledR}$, Merial Saúde Animal, Campinas, SP.

\section{REFERÊNCIAS}

1 Alves L.C., Ramos Q.F.C. \& Pereira I.H.O. 1993. Ocorrência de Lynxacarus radovskyi em felinos na cidade de Recife. Revista Brasileira de Parasitologia Veterinária. 2 (Supl 1): 10.

2 Alves A., Flecher M.C., Picorelli L.G., Correa G.N.S. \& Pereira Neto E. 2006. Infestação por Felicola subrostratus e Lynxacarus radovskyi em gata: Relato de caso. In: IV Jornada Científica do Centro Universitário Vila Velha. (Vila Velha, Brasil).p.255.

3 Craig T.M., Tell P.D., Dubuisson L.M. \& Duibisson R.K. 1993. Lynxacarus radovskyi infestation in a cat. Journal of the American Veterinary Medical Association. 202: 613-614.

4 Faccini J.L.H. \& Coutinho V. 1986. Ocorrência de Lynxacarus radovskyi (Acari: Listrophoridae) em gatos domésticos no Brasil. Arquivo da Universidade Federal Rural do Rio de Janeiro - UFRJ. 9: 91-93.

5 Faustino M.A.G., Messias J.B. \& Romeiro E.T. 2004. Infestação por Lynxacarus radoviskyi (Tenório 1974) em felinos revisão. Clínica Veterinária. 53: 52-56.

6 Figueiredo F.B., Schubach T.M.P., Pereira S.A., Okamoto T., Santos I.B., Leme L.R.P. \& Faccini J.L.H. 2004. Relato de mais de 42 casos de linxacariose felina na região metropolitana da cidade do Rio de Janeiro, RJ, Brasil. Revista Brasileira de Parasitologia Veterinária. 13: 41-43.

7 Foley R.H. 1991. An epizootic of a rare fur mite in an island's cat population. Feline Practice. 19: 17-19.

8 Gondini L.F.P., Conceição L.G., Franco S.R.V.S. \& Kohayagawa A. 1994. Lynxacarus radovskyi em gatos: descrição de um caso. In: Congresso Brasileiro de Medicina Veterinária. (Olinda, Brasil). p.160.

9 Heath A.C.G. \& Mariadas B.A. 1999. A New Zealand record for the cat fur-mite Lynxacarus (Felistrophorus) radovskyi Tenorio (Acarina: Astigmata: Listrophoridae). New Zealand Veterinary Journal. 47: 211-212.

10 Lopes L.M.S., Lopes A.C.C. \& Serra-Freire N.M. 1997. Registro da lynxacariose em Felis catus domesticus na cidade de Jundiaí, Estado de São Paulo. Revista Brasileira de Ciências Veterinárias. 4: 43-44.

11 Mueller R.S. 2005. Superficial mites in small animal dermatology. In: $50^{\circ}$ Congresso Nazionale Multisala SCIVAC. Rimini, Itália. [FONTE: <http://www.ivis.org/proceedings/scivac/2005/Mueller4_en.pdf?LA=1>].

12 Payne P.A., Dryden M.W. \& Carter G.R. 2005. External Parasitic Diseases of Dogs and Cats. In: Carter G.R. \& Payne P.A. (Eds). A Concise Guide to Infectious and Parasitic Diseases of Dogs and Cats. International Veterinary Information Service. [FONTE: <http://www.ivis.org/signin.asp?url=/special_books/carter/carter7/chapter.asp?LA=1>]

13 Pereira M.C. 1996. The cat fur mite (Lynxacarus radovskyi) in Brazil. Feline Practice. 24: 24-26.

14 Pollmeier M., Pengo G., Longo M. \& Jeannin P. 2004. Effective treatment and control of biting lice, Felicola subrostratus (Nitzsch in Burmeister, 1838), on cats using fipronil formulations. Veterinary Parasitology. 121: 157-165

15 Porto W.J.N., Wanderlei F.S., Alves L.C., Godoy S.S. \& Oliveira L.P.L. 2002. Ocorrência do Lynxacarus radovskyi (Tenório, 1974) em gatos domésticos (Felis catus) na cidade de Maceió - AL. In: Congresso Brasileiro de Parasitologia Veterinária. (Rio de Janeiro, Brasil). p.65.

16 Ribeiro V.L.S., Oliveira C.M.B., Seibert M., Gonçalves I.D. \& Faraco C.E.C. 1997. Ocorrência de Lynxacarus radovskyi (Tenório, 1974) em gatos domésticos (Felis catus) no Rio Grande do Sul. In: Congresso Brasileiro de Medicina Veterinária. (Gramado, Brasil). p.190. 
Aguiar J., Machado M.L.S., Ferreira R.R., Hünning P.S., Muschner A.C. \& Ramos R.Z. 2009. Infestação mista por Lynxacarus

radovskyi e Felicola subrostratus em um gato na região de Porto Alegre, RS, Brasil. Acta Scientiae Veterinariae. 37 (3): $301-305$.

17 Romeiro E.T., Fautino M.A.G., Alves L.C., Soares Y.M.V. \& Matoso U.N.V. 2007. Aspectos clínicos da infestação por Lynxacarus radovskyi em gatos procedentes da Região Metropolitana do Recife. Revista Clínica Veterinária. 69: 108-113.

18 Santos A.C.G., Mariz M.A.S., Amorim M.G.R., Santos S.B. \& Araújo-Lima R.C. 2001. Relato de Lynxacarus radovskyi Tenório, 1974 (Acari: Listrophoridae) em gatos domésticos na cidade de Natal - RN. In: Congresso Brasileiro de Medicina Veterinária (Salvador, Brasil). p.183.

19 Serra-Freire N.M., Benigno R.N.M., Oliveira S.A., Lopes L.M.S. \& Galvão G. 2002. Lynxacarus radovskyi - Diagnóstico e Tratamento em felinos de Belém, Pará. Revista Universidade Rural. Série Ciências da Vida. 22: 57-60.

20 Scott D.W., Miller H.W. \& Griffin C.E. 1996. Doenças parasitárias da pele. In: Muller and Kirk Dermatologia dos pequenos animais. 5.ed. São Paulo: Manole, pp.374-376.

21 Tenório J.M. 1974. A new species of Lynxacarus (Acarina: Astigmata: Listrophoridae) from Felis catus in the Hawaiian Islands. Journal Medical Entomology. 11: 599-604. 